\title{
Current concepts in the assessment and management of multiligament injuries of the knee
}

\author{
Waldo Scheepers ${ }^{1}{ }^{*}$ (1), Vikas Khanduja ${ }^{2}$ (D), and Michael Held ${ }^{1}$ (C) \\ ${ }^{1}$ Department of Orthopedic Surgery, Groote Schuur Hospital, Orthopedic Research Unit, University of Cape Town, \\ 7925 Cape Town, South Africa \\ ${ }^{2}$ Consultant Orthopedic Surgeon, Addenbrooke's - Cambridge University Hospital, Cambridge CB2 0QQ, United Kingdom
}

Received 9 August 2021, Accepted 29 October 2021, Published online 6 December 2021

\begin{abstract}
Multiligament knee injuries (MLKIs), though rare, pose significant challenges to the patient and surgeon. They often occur in the setting of high-velocity trauma and are frequently associated with concomitant intra- and extraarticular injuries, the most immediately devastating of which is vascular compromise. A detailed evaluation is required when acute or chronic MLKIs are suspected, and stress radiography, MRI and angiography are valuable adjuncts to a thorough clinical examination. Surgical treatment is widely regarded as superior to non-surgical management and has been demonstrated to improve functional outcome scores, return to work, and return to sport rates, though the incidence of post-traumatic osteoarthritis remains high in affected knees. However, acceptable results have been obtained with conservative management in populations where surgical intervention is not feasible. Early arthroscopic single-stage reconstruction is currently the mainstay of treatment for these injuries, but some recent comparative studies have found no significant differences in outcomes. Recent trends in the literature on MLKIs seem to favour early surgery over delayed surgery, though both methods have distinct advantages and disadvantages. Due to the heterogeneity of the injury and the diversity of patient factors, treatment needs to be individualised, and a single best approach with regards to the timing of surgery, repair versus reconstruction, surgical technique and surgical principles cannot be advocated. There is much controversy in the literature surrounding these topics. Early post-operative rehabilitation remains one of the most important positive prognostic factors in surgical management and requires a dedicated team-based approach. Though outcomes of MLKIs are generally favourable, complications are abundant and precautionary measures should be implemented where possible. Low resource settings are faced with unique challenges, necessitating adaptability and pragmatism in tailoring a management strategy capable of achieving comparable outcomes.
\end{abstract}

Key words: Multiligament knee injuries, Knee dislocations, Assessment, Management, Review.

\section{Introduction}

A knee dislocation (KD) is defined as tibiofemoral disarticulation, but spontaneous reduction and KDs with intact cruciate ligaments have added complexity to this definition [1]. The term multiligament knee injury (MLKI) is therefore used with less ambiguity when two or more of the four main knee ligaments are injured: these are the anterior cruciate ligament (ACL), posterior cruciate ligament (PCL), posterolateral corner (PLC) and posteromedial corner (PMC) [2]. KDs are rare, with an estimated $0.02-0.2 \%$ of orthopaedic injuries, but the true incidence is likely to be underestimated due to spontaneous reduction or missed injuries in the polytrauma patient $[3,4]$.

\footnotetext{
*Corresponding author: waldoscheepers@gmail.com
}

In 1824, Sir Astley Cooper made the observation about knee dislocations: "Of this, I have only seen one instance, and I conclude it, therefore, to be a rare occurrence; and there are scarcely any accidents to which the body is more liable which more imperiously demand immediate amputation than these." [5] Consequently, KDs were historically associated with detrimental sequelae such as loss of life and limb, and initial management focused on conservative strategies [6-9]. This has changed as surgical techniques and intricate anatomic and biomechanical knowledge evolved [10]. Yet, some of these historical findings are still applicable in certain settings.

The scarcity and heterogeneity of this injury make adequately powered prospective clinical trials in a similar setting challenging, resulting in a paucity of high-level evidence [11]. Consequently, there is much controversy in the literature about surgical versus non-surgical management, repair versus 
reconstruction, surgical techniques and the ideal timing of MLKI surgery. This creates the need for interpretation and contemporary insight into the specific considerations that need to be taken into account when tailoring an individualised, evidence-based approach to managing a multiple-ligament injured knee. Therefore, the aim of this article is to review, debate, and critically interrogate the current literature to provide an overview of the background, assessment, management, and outcomes of MLKIs.

\section{Etiology}

KDs can result from high-, low- and ultra-low-velocity injuries. High-velocity injuries are usually caused by motor-vehicle accidents, falls from a significant height or severe crush injuries and are more likely to have associated injuries [12, 13]. Most low-velocity knee dislocations occur during sporting activities or falls from less than approximately $1.5 \mathrm{~m}$ and typically have better overall outcomes $[12,13]$. Ultra-low velocity KDs mostly occur in obese patients and are often sustained during activities of daily living [12]. With the current obesity pandemic, these injuries have become more frequent, leading to a demographic peak of the obese elderly population, besides young patients with high-energy injuries [14]. The obese patients are especially challenging to examine [11], which can be detrimental as they present a higher rate of associated injuries and post-operative complications than non-obese patients [15].

\section{Classification}

The Schenck classification system is most commonly used to categorise knee dislocations [11]. It describes the anatomical pattern of ligamentous disruption and has been modified to include specifiers for neurovascular injuries. More detail can be added for each of these grades (i.e. via Müeller charts), which could potentially aid surgical planning [11] and add prognostic value for clinical outcome [16]. The positional Kennedy classification and other energy-based classification systems have been found inadequate for communication or guiding management as they are limited in describing the severity and pattern of ligamentous injury - especially in cases of spontaneous reduction [17].

\section{Associated injuries}

There is a high incidence of intra-and extra-articular injuries in MLKIs. The presence of meniscal or chondral injuries has been reported in up to $76 \%$ of cases $(55 \%$ and $48 \%$, respectively) [18]. Associated vascular injuries are common and potentially devastating, with amputation rates of $12 \%[3,19]$, which rises to $80 \%$ if limb ischaemia exceeds $8 \mathrm{~h}$ [20]. In a systematic review of 23 studies and 907 patients, an $18 \%$ incidence of vascular injuries in KDs was found, with a rate of $32 \%$ in Schenck KDIIIL patterns [19]. The popliteal artery is most frequently affected in $83.6 \%$ of cases, followed by the tibial artery in $7.54 \%$ of cases [20]. The incidence of associated neurological injury varies greatly in literature (5-59\%), with a 2014 systematic review by Medina et al. including 862 patients

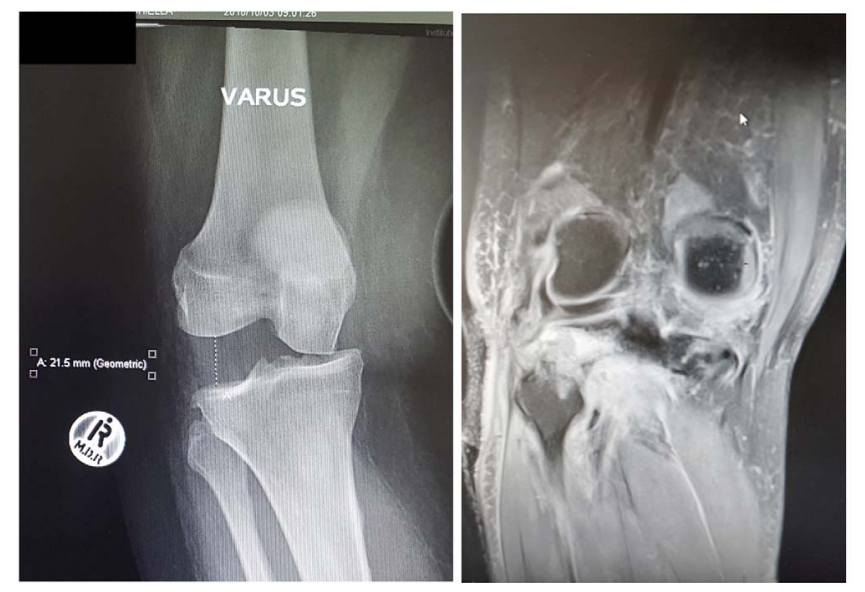

Figure 1. Imaging in a patient with a suspected MLKI. Left: AP varus stress radiograph shows a large lateral joint gap indicative of a complete disruption of the LCL, associated disruption of cruciate ligaments should be suspected. Right: The injury can also be seen on coronal T2 MRI with disruption of the posterolateral complex.

estimating it at 25\% [19]. A retrospective review of the American College of Surgeons National Trauma Data Bank, including 6454 patients, reported an incidence of $6.2 \%$ [20]. The common peroneal nerve (CPN) is most often affected $(53.3 \%)$ and is associated with posterolateral corner injuries in $21.6 \%$ of cases [21]. The resultant loss of antigravity strength is potentially disabling [22]. Furthermore, the presence of an open injury significantly complicates management as they often occur in the setting of high-velocity polytrauma with substantial damage to surrounding soft-tissues [23]. Open injuries occur in $13.6 \%$ of KDs [20] and carry a greater infection risk of up to $43 \%$ [23]. They also constitute a risk factor for vascular injury [21] and raise the amputation rate to $15.6 \%$ [20].

\section{Evaluation}

A detailed history and clinical examination should precede available imaging techniques. Magnetic resonance imaging (MRI) has become the gold standard in the evaluation of injured structures [24], but stress radiography remains useful in both acute and chronic injuries, especially if MRI is not available (Figure 1) [25].

\section{Acute injuries}

The initial assessment must abide by advanced trauma life support (ATLS) principles as MLKIs are frequently complicated by comorbid polytrauma [26]. A thorough neurovascular exam is always warranted, and an Ankle Brachial Index (ABI) should be performed [27] and serially monitored as the development of occlusive thromboses formed by intimal flap tears may only be revealed with time [28]. An ABI $<0.9$ or an expanding haematoma indicates angiography [29], and CT or MRI angiography should be considered a first-line modality for diagnosing arterial injury [27]. In many Level 1 centres in high-resource settings, polytrauma patients routinely undergo whole-body CT scans on arrival with CT angiography for 
Table 1. Evaluation of posterior, varus and valgus knee instability using stress radiographs [25].

\begin{tabular}{|c|c|c|c|c|c|c|}
\hline \multicolumn{3}{|c|}{ Poster instability } & \multicolumn{2}{|c|}{ Varus instability } & \multicolumn{2}{|c|}{ Valgus instability } \\
\hline $\begin{array}{l}\text { Kneeling stress } \\
\text { radiographs (PTT) }\end{array}$ & Injury & $\begin{array}{l}\text { Grade of PCL } \\
\text { injury }\end{array}$ & $\begin{array}{l}\text { Varus stress } \\
\text { test }\end{array}$ & Injury & Valgus stress test & Injury \\
\hline$\leq 7 \mathrm{~mm}$ & Normal or partial tear & $\mathrm{I}$ & $\leq 2.6 \mathrm{~mm}$ & $\begin{array}{l}\text { Normal or } \\
\text { partial tear }\end{array}$ & $\leq 3.1 \mathrm{~mm}$ & Normal or partial tear \\
\hline $8-11 \mathrm{~mm}$ & Complete PCL tear & II & $2.7-3.9 \mathrm{~mm}$ & Isolated LCL tear & $3.2-9.7 \mathrm{~mm}$ & Complete sMCL tear \\
\hline$\geq 12 \mathrm{~mm}$ & $\begin{array}{l}\text { Combined ligament } \\
\text { injury }\end{array}$ & III & $\geq 4 \mathrm{~mm}$ & Complete PLC injury & $\geq 9.8 \mathrm{~mm}$ & $\begin{array}{l}\text { Complete tear of } \\
\text { all medial structures }\end{array}$ \\
\hline
\end{tabular}

LCL, lateral collateral ligament; PCL, posterior collateral ligament; PLC, posterolateral corner; PTT, posterior tibial translation; sMCL, superficial medial collateral ligament.

suspected KDs. Traditionally, arteriography has been the gold standard for detecting vascular injuries but is expensive, requires arterial puncture and has a complication rate of up to $9 \%$ [30]. If an arterial injury is found, acute revascularisation is required, and the limb should be immobilised, ideally in a transarticular external fixator for 2-6 weeks to preserve the integrity of the vascular graft and joint reduction keeping in mind the risk of pin tract infection and joint stiffness [25, 27].

\section{Chronic injuries}

As a result of spontaneous reduction of KDs in up to $50 \%$ of cases and concomitant polytrauma, MLKIs are often missed in the acute setting [4]. Here as well, MRI plays a pivotal role in assessing damaged intra-articular structures and should be routinely used when available [25]. Comparative stress radiographs can objectively and dynamically assess the laxity of healed but elongated ligaments which are often overlooked, especially in chronic PCL or MCL tears on MRI scans [27].

Moatshe et al. have devised a grading system of instability of the PCL, LCL, and MCL based on stress radiographs by comparing the injured and uninjured knees (Table 1) [25]. The mechanical axis should also be determined radiographically to detect malalignment prior to ligament reconstruction [25]. If varus malalignment is present in chronic PLC injuries, a corrective osteotomy should be considered prior to reconstruction to prevent excessive graft tension and failure [25].

\section{Surgical versus non-surgical management}

Surgical treatment of MLKIs is widely regarded as superior to non-surgical management. Dedmond and Almekinders performed a meta-analysis that assessed surgically and nonsurgically treated knees and demonstrated a better range of motion, flexion contractures and Lysholm scores in the surgically treated group [10]. An evidence-based review by Peskun and Whelan found that surgical versus non-surgical management improved Lysholm scores, IKDC scores, and Tegner activity scores. The differences in IKDC and Tegner activity scores were not statistically significant. No significant differences were found in ROM between groups, but improvements in instability as assessed by KT-1000 ${ }^{\mathrm{TM}}$ measurements were found in the operative cohort. Return to employment and return to a comparable level of athletic competition were considerably higher with surgery [31]. A systematic review by Levy et al. found im- proved IKDC scores, return to work rates and return to full sport rates in the surgical cohorts [2]. Plancher et al. retrospectively evaluated 50 knees, of which 31 were treated surgically and 19 conservatively and found that the surgical cohort was significantly less likely to develop severe radiographic degenerative changes (47.4\% and $88 \%$, respectively) [32, 33]. Most smaller retrospective studies have found similar improvements in surgically treated patients when assessing range of motion and functional outcome scores (Table 2) [34-38].

Although surgical treatment has been demonstrated to be superior to non-surgical treatment, a pragmatic approach should be taken, and surgery might not always be feasible in lowresource settings (LRS). Closed reduction, immobilisation with an external fixator or cast for 4-6 weeks and a period of nonweight-bearing has been reported to attain acceptable outcomes in cases where surgery is not feasible, but regular radiographic evaluation to ensure that reduction is maintained is essential [39-41]. Range of motion can subsequently be improved with manipulation under anaesthesia or arthroscopic adhesiolysis after immobilisation [40]. However, data supporting conservative management is old, and advances in surgical methods have affirmed the superiority of operative treatment. Non-operative treatment should only be considered when surgical intervention is unavailable and in special populations such as the morbidly obese, patients with vascular or open injuries, patients unable to attend rehabilitation, the elderly and comorbid-burdened patients [25, 40].

\section{Repair versus reconstruction}

Multiligament injured knees can either be repaired with sutures or reconstructed with the use of various grafts. Repair is ideally performed in the acute period (within 3 weeks of the injury), whereas reconstruction can be done early, later or in stages [42]. Staged surgery consists of acute primary repair of collateral ligaments with cruciate reconstruction once improved range of motion has been obtained, and good outcomes have been reported for range of motion and stability [43, 44]. Systematic reviews by Jiang et al. and Mook et al. found improved subjective outcomes and range of motion with staged procedures [45, 46]. However, a meta-analysis by Frosch et al. compared suture repair versus reconstruction of cruciate ligaments and found that a two-staged procedure wherein collateral ligaments are repaired without addressing the cruciate ligaments cannot be recommended [47]. A staged 
Table 2. Outcome comparison of surgical versus nonsurgical treatment [2, 10, 31, 34-38].

\begin{tabular}{|c|c|c|c|c|c|c|c|c|c|c|c|c|c|c|c|c|c|}
\hline \multirow[t]{2}{*}{ Study } & \multirow[t]{2}{*}{ Design } & \multicolumn{2}{|c|}{$\begin{array}{c}\text { Number } \\
\text { of } \\
\text { patients }\end{array}$} & \multicolumn{2}{|c|}{$\begin{array}{l}\text { Lysholm } \\
\text { Score }\end{array}$} & \multicolumn{2}{|c|}{$\begin{array}{l}\text { IKDC Score } \\
\text { (\% Good/ } \\
\text { excellent) }\end{array}$} & \multicolumn{2}{|c|}{$\begin{array}{l}\text { Tegner } \\
\text { activity } \\
\text { score }\end{array}$} & \multicolumn{2}{|c|}{$\begin{array}{c}\text { Range of } \\
\text { motion } \\
\left({ }^{\circ}\right)\end{array}$} & \multicolumn{2}{|c|}{$\begin{array}{l}\text { Loss of } \\
\text { flexion } \\
\left({ }^{\circ}\right)\end{array}$} & \multicolumn{2}{|c|}{$\begin{array}{l}\text { Return to } \\
\text { work (\%) }\end{array}$} & \multicolumn{2}{|c|}{$\begin{array}{l}\text { Return to } \\
\text { sport }(\%)\end{array}$} \\
\hline & & $\mathrm{S}$ & NS & $\mathrm{S}$ & NS & $S$ & NS & $\mathrm{S}$ & NS & $\mathrm{S}$ & NS & $\mathrm{S}$ & NS & $\mathrm{S}$ & NS & $\mathrm{S}$ & NS \\
\hline $\begin{array}{l}\text { Dedmond and } \\
\text { Almekinders [10] }\end{array}$ & Meta-analysis & 132 & 74 & 85.2 & 66.5 & & & & & 123 & 108 & 0.54 & 3.5 & 58 & 50 & 31 & 14 \\
\hline Levy et al. [2] & $\begin{array}{c}\text { Systematic } \\
\text { Review }\end{array}$ & 227 & 107 & & & 58 & 20 & & & 126 & 123 & 4 & 3 & 72 & 52 & 29 & 10 \\
\hline $\begin{array}{l}\text { Peskun and Whelan } \\
\text { [31] }\end{array}$ & $\begin{array}{l}\text { Systematic } \\
\text { Review }\end{array}$ & 855 & 61 & 84.3 & 67.2 & 61.3 & 25.0 & 4.8 & 2.7 & & & & & 80.9 & 50 & 57.8 & 22.2 \\
\hline $\begin{array}{l}\text { Almekinders and } \\
\text { Logan [35] }\end{array}$ & $\begin{array}{l}\text { Retrospective } \\
\text { Study }\end{array}$ & 6 & 10 & & & & & & & 129 & 108 & & & & & & \\
\hline Richter et al. [34] & $\begin{array}{l}\text { Retrospective } \\
\text { cohort }\end{array}$ & 59 & 18 & 78 & 65 & 24 & 6 & 4 & 3 & & & & & 85 & 53 & 56 & 17 \\
\hline Wong et al. [38] & $\begin{array}{l}\text { Retrospective } \\
\text { cohort }\end{array}$ & 15 & 11 & & & 75.84 & 63.71 & & & 129 & 137 & 6 & 2 & & & 0 & 0 \\
\hline Ríos et al. [37] & $\begin{array}{l}\text { Retrospective } \\
\text { cohort }\end{array}$ & 21 & 5 & 77 & 40 & 76 & 0 & & & & & & & & & & \\
\hline Demirağ et al. [36] & $\begin{array}{l}\text { Retrospective } \\
\text { cohort }\end{array}$ & 6 & 6 & 84.6 & 74 & & & & & 116 & 72 & & & & & & \\
\hline
\end{tabular}

Abbreviations: S, Surgical; NS, Non-surgical.

reconstruction can cause altered joint kinematics and increase the risk of graft failure, thus single-stage reconstruction is advocated by some authors to avoid this complication while facilitating early mobilisation and mitigating joint stiffness [25]. Though acceptable results have been reported with both repair and reconstruction, repair of the MCL generally does not offer benefit over nonoperative treatment [47]. In many studies that include bicruciate injuries, the repair cohort underwent PCL suturing, and the ACL was left untreated, making the accurate comparison of repair versus reconstruction challenging [47]. The heterogeneity of knee injuries and lack of high-level evidence on the matter necessitates individualised consideration when choosing an approach [48].

Mariani et al. demonstrated that reconstruction yielded better stability, range of motion, functional outcome scores and return to pre-injury activities [49]. However, this data is more than 2 decades old. A meta-analysis by Frosch et al. reported good or excellent IKDC or Lysholm scores with both methods and found no significant difference between the two [47]. A systematic review by Levy et al. showed similar functional outcome scores with repair and reconstruction, but stability, ROM and return to pre-injury activity levels was higher in the reconstruction cohort [2]. A combined repair-reconstruction approach has been advocated if collateral ligaments and extra-articular structures are affected [50]. Historically, posterolateral corner injuries treated with reconstruction have lower reoperation rates than when repaired [2, 25, 42]. Stannard et al. found failure rates of $37 \%$ with PLC repair compared to $9 \%$ failure with reconstruction. It should be noted that about half of the patients in both the repair and reconstruction groups (48.5\% and 54.5\%, respectively) had a hinged external fixator post-operatively [51]. Similarly, Levy et al. compared LCL/PLC repair and reconstruction and found failure rates of $40 \%$ and $6 \%$, respectively [52]. Therefore reconstruction is widely accepted as goldstandard, although some recent prospective and retrospective studies have found no significant differences in outcomes between methods [48]. There also seems to be no clear difference comparing repair to reconstruction regarding medial collateral ligaments and posteromedial corner injuries [42]. Repair is generally favoured for avulsion fractures [40, 42, 48] and has been advocated when ligaments are torn at their insertions [53]. A recent resurgence of interest in repair has been brought about with the introduction of internal bracing, in which primary repairs are synthetically augmented [40, 54, 55]. LRS may benefit from this method as surgical time is reduced by avoiding graft harvesting, and the stability of a primary repair is enhanced [40]. Equivalent outcome results have been reported with this method [54, 56]. A recent descriptive cross-sectional scenario-based survey compared approaches to MLKI management between surgeons in emerging markets and developing nations (EMDNs) and developed economic nations (DENs). It found that surgeons from EMDNs preferred conservative management and delayed staged reconstruction with autograft and often did not have access to a physiotherapist. DENs surgeons favour early, single-stage arthroscopic ligament reconstruction [57].

\section{Timing}

Conflicting data exist about the ideal timing of surgery for MLKIs. Additionally, there is ambiguity about the time frame defining "early" and "delayed" surgery [42, 48, 58]. Early surgery has typically been described as an intervention within 3 weeks of the injury, when soft-tissue integrity is intact, and tissue planes are still definable [48], whereas late surgery refers to intervention after 4-6 weeks [58]. Advantages of early surgery include earlier restoration of normal joint kinematics and earlier mobilisation, which may improve functional outcomes, though there is an increase in arthrofibrosis and knee stiffness [40, 42]. Delayed reconstruction allows extra-articular structures to heal, improving ROM and potentially avoiding additional 
unnecessary surgery, but is associated with a higher risk of further chondral or meniscal damage [40, 42]. Early post-operative rehabilitation is the most important positive prognostic factor, regardless of the timing of surgery [40]. Thus delayed reconstruction is an attractive option in LRS as structures may heal independently and negate unnecessary interventions, and where proper rehabilitation is not readily available. Though controversial, overall recent trends in literature seem to favour early surgery with improved or similar outcomes compared to delayed surgery [2, 42, 44, 48, 58-60].

\section{Surgical techniques}

Various surgical techniques have been described and need to be tailored to the patient and thorough pre-operative assessment. Historically, open repair of all ligaments was advocated, an approach that is now outdated [61]. Acute arthroscopic single-stage reconstruction is the current gold-standard treatment for ligamentous injuries but is not always available [40, 62]. Furthermore, if arthroscopy is performed too soon in MLKI, it may result in fluid extravasation and compartment syndrome due to capsular disruption [63]. Therefore, some recommend delaying surgery by 10-14 days to allow swelling to subside and capsular healing [63]. Open surgery is performed where arthroscopy is not feasible (Figure 2).

If reconstruction is chosen, graft selection includes autografts, allografts and synthetic grafts - each with a set of distinct advantages and disadvantages (Table 3) [42, 64]. Fixation is dependent on graft choice, and graft size is another important consideration (Table 4) [64, 65]. Graft selection is dependent on the preference of the surgeon and patient, availability, and the number of injured ligaments to be reconstructed [65].

Both the ACL and PCL can be reconstructed with single- or double-bundles techniques. For the ACL, single-bundle reconstruction is currently favoured [40]. Double-bundle reconstruction of the PCL has been shown to better replicate normal knee kinematics and reduce residual posterior translation, although clinical outcomes remain similar [42]. Good results have been reported with single-staged and two-staged procedures, and the ultimate decision is dependent on resources as well as the surgeon's preference and ability [58]. The distinct advantage of single-stage surgery lies in facilitating early mobilisation and preventing joint stiffness [25]. In vascular repairs, open injuries, gross obesity, or in selected cases with severe instability, an external fixation device can be indicated to achieve initial stability [24].

\section{Rehabilitation}

Post-operative treatment needs to be individualised, and the outcome is dependent on the cooperation of the patient, surgeon and multi-disciplinary team involved. Most experts recommend an initial period of non-weight-bearing for 4-6 weeks, followed by active mobilization and progressive weight-bearing [48]. Early surgery combined with early motion (defined as achieving greater than 30 degrees motion within 3 weeks of surgery) has been found to reduce posterior instability, varus and valgus laxity, flexion loss of more than $10^{\circ}$, extension loss of more

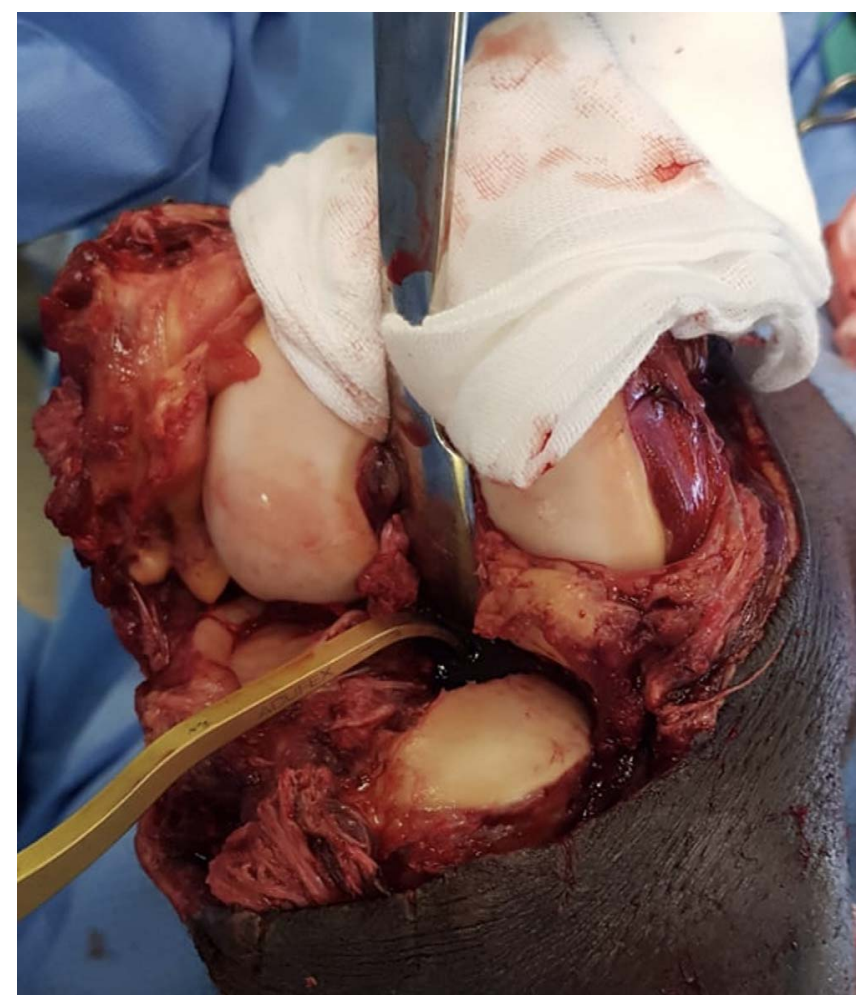

Figure 2. Open surgery in a patient with a traumatic knee arthrotomy and MLKI. Open cruciate surgery done in a patient with an open knee dislocation, patella tendon rupture and large traumatic arthrotomy. The PCL tunnel is drilled under direct vision with a PCL tunnel aimer.

than $5^{\circ}$ and results in improved outcome scores when compared to early surgery with delayed rehabilitation [66]. However, strength often remains poor at 2 years after surgery for MLKIs with notable deficits in both quadriceps and hamstrings [66]. The importance of rehabilitation and early mobilisation has historically been a cardinal factor in achieving desirable outcomes and remains relevant today [61].

\section{Outcomes}

Although most studies of MLKIs treated surgically consist of small cohorts with short follow-up periods, surgical management of these injuries results in good functional outcomes as assessed by validated scoring systems [10]. However, the outcome can vary with IKDC scores as low as 67 [3] and as high as 82 [67] on medium-term follow-up. The incidence of radiographic osteoarthritis (OA) varies in the literature, with reports of $23 \%$, by Fanelli et al. [68] $42 \%$ by Moatshe et al. [33] and $87 \%$ by Engebretsen et al. [69] over follow-up periods of 2-12 years. Only $6.8 \%$ of the patients in the study by Fanelli et al. eventually underwent total knee arthroplasty [68], with Moatshe et al. demonstrating a similar rate of 7.7\% [33]. Regarding revision MLKI reconstruction, Woodmass et al. assessed the outcomes in 23 patients at a mean of 7.5 years follow-up and found average Lysholm and IKDC scores of 79.4 and 74.5, respectively [70]. The Multiligament Quality of Life (ML-QOL) scoring system designed by Chahal et al. has Q5 
Table 3. A comparison of autografts versus allografts [63].

\begin{tabular}{lll}
\hline & Autograft & Allograft \\
\hline Cost & No additional cost & Additional cost \\
Availability & Readily available & May not be readily available \\
Risk & No risk of disease transmission & Risk of disease transmission \\
& Additional surgical risks & No additional surgical risks \\
Quality & Good quality & Quality may be reduced if irradiated (relevant in low-resource \\
& & settings with a high burden of transmissible disease) \\
Morbidity & Donor site morbidity & No donor site morbidity \\
Operating time & Less operating time & More operating time \\
Tissue reaction & Minimal & Variable \\
\hline
\end{tabular}

Table 4. Advantages and disadvantages of different grafts [64, 65].

\begin{tabular}{|c|c|c|}
\hline Graft & Advantages & Disadvantages \\
\hline \multirow[t]{4}{*}{ Bone - Patella Tendon - Bone } & Large grafts & Risk of patella fracture \\
\hline & Bone-to-bone healing & Anterior knee pain \\
\hline & Less graft stretching & Quadriceps weakening \\
\hline & Lower incidence of tunnel widening and rupture & \\
\hline \multirow[t]{3}{*}{ Quadriceps tendon } & Large cross-sectional area & Technically challenging to harvest \\
\hline & Low donor-site morbidity & \\
\hline & Bone-to-bone healing on one end & \\
\hline \multirow[t]{3}{*}{ Peroneus longus tendon } & Long graft & Risk of ankle pain and instability \\
\hline & Large cross-sectional area & \\
\hline & Simple harvest technique & \\
\hline \multirow{5}{*}{$\begin{array}{l}\text { Achilles tendon or tibialis } \\
\text { anterior allografts }\end{array}$} & No donor site morbidity & Low quality when irradiated \\
\hline & Shorter operation time & Risk of disease transmission when not irradiated \\
\hline & No size limitation & Local bone resorption \\
\hline & & Delayed incorporation \\
\hline & & Additional costs \\
\hline \multirow{6}{*}{$\begin{array}{l}\text { Hamstring (gracilis and } \\
\text { semitendinosus) }\end{array}$} & No anterior knee pain & Prolonged ligamentization and soft-tissue healing \\
\hline & & Haematoma formation \\
\hline & Low donor site morbidity & Poor predictability of graft size \\
\hline & Fast graft acquisition & Weakening of ACL agonists \\
\hline & Easy graft preparation and passage & Reduced speed in athletes \\
\hline & High load to failure & \\
\hline
\end{tabular}

recently gained attention to evaluate MLKIs as it is a diseasespecific questionnaire consisting of four relevant subsections - physical, emotional, activity and social subscales [71, 72]. Increased risk of $\mathrm{OA}$ is associated with high-energy trauma, age over 30 years and associated cartilage injuries [40]. A systematic review and meta-analysis by Poulsen et al. analysed approximately one million patients with various knee injuries and found a four times greater risk of developing OA with ACL injuries when compared to non-injured knees and a six fold increase with combined ACL and meniscal injuries [73]. In a retrospective cohort study, Richter et al. found that the degree of radiological OA as measured by the Jäger and Wirth Score correlated with the incidence of MCL and LCL ruptures and with knee stability at follow-up, not with the incidence of meniscal damage $[34,40]$. However, not all patients with radiological OA have symptoms [74]. Though controversial, several authors have advocated that early surgery reduces the risk of severe OA [74]. In cases of intractable pain and functional limitations caused by severe OA, total knee arthroplasty may offer relief. Poor functional outcomes are also associated with high-energy trauma and patient age over 30 years, and additionally with the repair of medial sided injuries and combined medial and lateral meniscal tears [25].

Everhart et al. performed a systematic review of 21 studies, including 524 patients, to determine overall rates of return to work or sport after MLKI. They found a return to any level of sport was $53.6 \%$, with a return to high-level sport significantly lower at $22-33 \%$ [75]. Return to any work was possible for $88.4 \%$ of patients, although only $62.1 \%$ could do so with minimal modifications [75]. Return to work was lower in patients with Schenck Grade IV and V injuries, as well as in patients with vascular injuries. Obese patients had worse Tegner activity scores when compared to the non-obese (mean scores of 1.7 vs. 4.5) [75].

\section{Complications}

Complications of MLKI are extensive, they can be acute or chronic and may be injury or intervention related. Vascular 


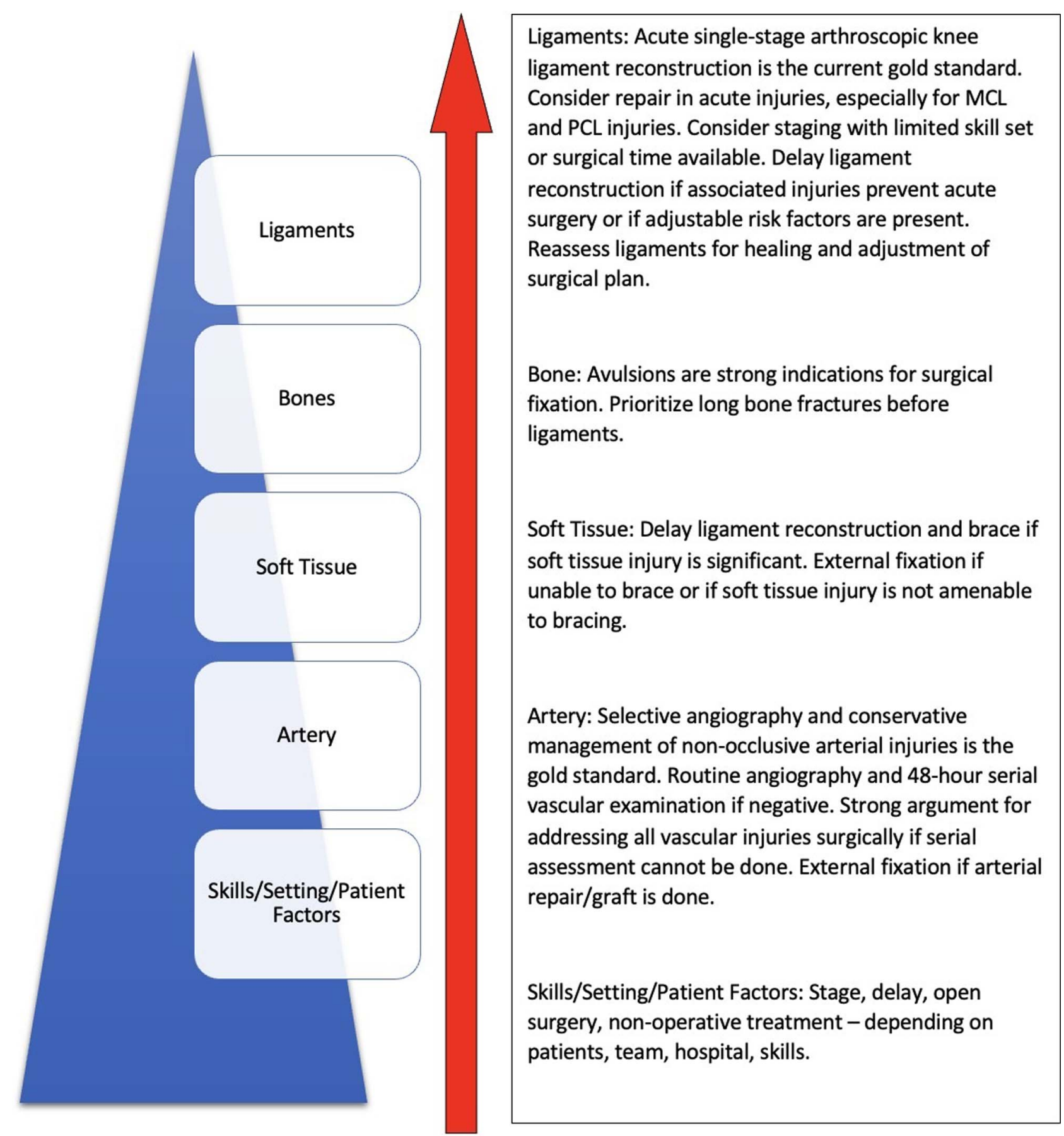

Figure 3. Pyramid of priorities when choosing an approach for knee ligament reconstruction. A summary of arguments for various approaches outlines the considerations when choosing an approach specific to knee ligament reconstruction. The pyramid of priorities in order of importance includes life-threatening injuries, vascular compromise, soft-tissue damage, fractures, and ligamentous injury. Available skills, the setting and patient factors will influence decision making at each step.

injuries are easily missed at presentation or caused iatrogenically, with the popliteal artery being placed at risk during PCL reconstruction [76]. Nerve injuries are also common and often result from the injury itself, though the peroneal nerve is at risk of injury during PLC repair and reconstruction [76]. Patients are predisposed to venous thromboembolic events and pulmonary emboli after MLKI surgery, but the risk can be mitigated with routine thromboprophylaxis [76]. Arthrofi- brosis after surgery poses another challenge that can be seen in up to $29 \%$ of patients after surgery, especially if performed in the acute phase [76]. Twenty one percent of these require manipulation under anaesthesia and potentially arthroscopic or open surgical adhesiolysis [76, 77].

Preventative measures constitute meticulous handling of soft-tissue, arthroscopy, minimising ipsilateral autografts, reduction of post-operative inflammation, and swelling and 
appropriate rehabilitation [76]. If significant capsular disruption or fascial damage is present, early arthroscopy within 1-2 weeks of the injury may result in fluid extravasation and compartment syndrome [63, 76]. Heterotropic ossification, avascular necrosis and fractures secondary to loss of bone stock with surgical tunnelling and hardware implantation can occur [76]. Recurrent instability is another potential complication [40]. Fanelli et al. evaluated knee stability in a cohort of 44 patients and reported KT1000 ${ }^{\mathrm{TM}}$ arthrometer side-to-side differences of $>5 \mathrm{~mm}$ in $16 \%$ of cases ( 7 patients), a similar rate of instability to other studies [68]. Post-operative infection rates are as high as $17 \%$ but can be reduced with the routine use of perioperative antibiotics [40]. Diabetics, the obese and patients undergoing prolonged surgery are predisposed to developing an infection [40]. Other intraoperative precautions include avoiding new incisions which cross scars or wounds, preserving skin bridges of at least $10 \mathrm{~cm}$ between incisions, careful soft-tissue handling, achieving proper haemostasis before wound closure, minimising tension with wound closure and using drains when needed to prevent haematoma formation [76]. Open injuries carry a much higher rate of post-operative infection, and immediate debridement, irrigation, intravenous antibiotics and external fixation is often warranted to reduce this risk [76].

\section{Authors' commentary}

As aforementioned, the heterogeneity of MLKIs and variation in patient and environmental factors necessitate an individualised approach when choosing a management plan. Above is a summary of arguments for various approaches that outline the considerations when choosing an approach specific to knee ligament reconstruction. The pyramid of priorities in order of importance includes life-threatening injuries, vascular compromise, soft-tissue damage, fractures and ligamentous injury. Available skills, the setting and patient factors will influence decision making at each step (Figure 3).

\section{Conclusion}

Multiligament knee injuries are challenging entities and are often missed in the presence of polytrauma. A high index of suspicion is required to detect associated injuries with potentially devastating complications. Vascular injuries are common, and a thorough clinical examination and monitoring of the limb are crucial. Angiography is indicated if the ABI is $<0.9$ or in the presence of an expanding haematoma. Stress radiography plays a pivotal role in evaluating both acute and chronic injuries, preand postoperatively. MRI should be used routinely where available. Knee dislocations are fraught with complications, both injury-related and iatrogenic, which can be mitigated with a thorough pre-operative assessment and complication-specific precautions. An open discussion with the patient about their expectations and likely outcomes is essential. Surgical treatment is superior to non-surgical treatment and results in good functional outcome scores, though in special populations and resource-restricted environments, conservative management is an acceptable treatment option. Despite favourable outcomes, the incidence of $\mathrm{OA}$ in the multiligament injured knee remains high. The importance of proper post-operative rehabilitation is emphasised repeatedly as a strong positive prognostic factor, and patient motivation remains a cornerstone to success. The heavy burden of MLKIs in LRS requires further consideration to address the unique challenges faced in their context. As evidenced by the literature, intense debate surrounds many aspects of MLKI surgery, such as timing, repair versus reconstruction and optimal tensioning sequences. This stresses the need for future research to produce high-level evidence on the topic, and the rapid evolution of technology and techniques will demand continuous and astute critical assessment.

\section{Conflicts of interest}

The authors declare they have no relevant financial or nonfinancial conflicts of interest to declare.

\section{Funding}

This research did not receive any specific funding.

\section{Ethical Approval}

Ethical approval was not required.

\section{Informed Consent}

This article does not contain any studies involving human subjects.

\section{Author Contributions}

W. Scheepers - writing original draft, editing; V. Khanduja - writing, reviewing, editing; M. Held - writing, reviewing, editing.

\section{References}

1. Seroyer ST, Musahl V, Harner CD (2008) Management of the acute knee dislocation: The Pittsburgh experience. Injury 39(7), 710-718.

2. Levy BA, Dajani KA, Whelan DB, et al. (2009) Decision making in the multiligament-injured knee: An evidence-based systematic review. Arthroscopy 25(4), 430-438.

3. Neri T, Myat D, Beach A, Parker DA (2019) Multiligament knee injury: Injury patterns, outcomes, and gait analysis. Clin Sports Med 38(2), 235-246.

4. Matthewson G, Kwapisz A, Sasyniuk T, MacDonald P (2019) Vascular injury in the multiligament injured knee. Clin Sports Med 38(2), 199-213.

5. Dhillon KS, Teng TK (1987) Traumatic dislocation of the knee. Med J Malaysia 42(3), 173-176.

6. Kennedy JC (1963) Complete dislocation of the knee joint. J Bone Joint Surg Am 45, 889-904. 
7. Taylor AR, Arden GP, Rainey HA (1972) Traumatic dislocation of the knee. A report of forty-three cases with special reference to conservative treatment. J Bone Joint Surg Br 54(1), 96-102.

8. Reckling FW, Peltier LF (1969) Acute knee dislocations and their complications. J Trauma Acute Care Surg 9(3), 181-191.

9. Lefrak EA (1976) Knee dislocation. An illusive cause of critical arterial occlusion. Arch Surg 111(9), 1021-1024.

10. Dedmond BT, Almekinders LC (2001) Operative versus nonoperative treatment of knee dislocations: A meta-analysis. Am J Knee Surg 14(1), 33-38.

11. Dosher WB, Maxwell GT, Warth RJ, Harner CD (2019) Multiple ligament knee injuries: Current state and proposed classification. Clin Sports Med 38(2), 183-192.

12. Azar FM, Brandt JC, Miller RH 3rd, Phillips BB (2011) Ultralow-velocity knee dislocations. Am J Sports Med 39(10), 2170 2174.

13. Darcy G, Edwards E, Hau R (2018) Epidemiology and outcomes of traumatic knee dislocations: Isolated vs multitrauma injuries. Injury 49(6), 1183-1187.

14. Arom GA, Yeranosian MG, Petrigliano FA, Terrell RD, McAllister DR (2014) The changing demographics of knee dislocation: A retrospective database review. Clin Orthop Relat Res 472(9), 2609-2614.

15. Werner BC, Gwathmey FW Jr., Higgins ST, Hart JM, Miller MD (2014) Ultra-low velocity knee dislocations: Patient characteristics, complications, and outcomes. Am J Sports Med 42(2), 358-363.

16. Maxwell G, Warth R, Amin A, et al. (2021) Multiple ligament knee injuries: Does the knee dislocation classification predict the type of surgical management? J Knee Surg 34(03), 273-279.

17. Goebel CP, Domes C (2020) Classifications in brief: The Schenck classification of knee dislocations. Clin Orthop Relat Res 478(6), 1368-1372.

18. Krych AJ, Sousa PL, King AH, Engasser WM, Stuart MJ, Levy BA (2015) Meniscal tears and articular cartilage damage in the dislocated knee. Knee Surg Sports Traumatol Arthrosc 23(10), 3019-3025.

19. Medina O, Arom GA, Yeranosian MG, Petrigliano FA, McAllister DR (2014) Vascular and nerve injury after knee dislocation: A systematic review. Clin Orthop Relat Res 472(9), 2621-2629.

20. Chowdhry M, Burchette D, Whelan D, Nathens A, Marks P, Wasserstein D (2020) Knee dislocation and associated injuries: An analysis of the American College Of Surgeons National Trauma Data Bank. Knee Surg Sports Traumatol Arthrosc 28 (2), 568-575.

21. Worley JR, Brimmo O, Nuelle CW, Cook JL, Stannard JP (2019) Incidence of concurrent peroneal nerve injury in multiligament knee injuries and outcomes after knee reconstruction. J Knee Surg 32(6), 560-564.

22. Krych AJ, Giuseffi SA, Kuzma SA, Stuart MJ, Levy BA (2014) Is peroneal nerve injury associated with worse function after knee dislocation? Clin Orthop Relat Res 472(9), 2630-2636.

23. King JJ 3rd, Cerynik DL, Blair JA, Harding SP, Tom JA (2009) Surgical outcomes after traumatic open knee dislocation. Knee Surg Sports Traumatol Arthrosc 17(9), 1027-1032.

24. Romeyn RL, Jennings J, Davies GJ (2008) Surgical treatment and rehabilitation of combined complex ligament injuries. $\mathrm{N}$ Am J Sports Phys Ther 3(4), 212-225.

25. Moatshe G, Chahla J, LaPrade RF, Engebretsen L (2017) Diagnosis and treatment of multiligament knee injury: State of the art. JISAKOS 2(3), 152-161.
26. Moatshe G, Dornan GJ, Loken S, Ludvigsen TC, LaPrade RF, Engebretsen L (2017) Demographics and injuries associated with knee dislocation: A prospective review of 303 patients. Orthop J Sports Med 5(5), 2325967117706521.

27. Richter DL, Held M, Campos T, Wascher DC, Schenck RC (2020) The management of knee dislocations in the limitedresource setting. J Bone Joint Surg 102, e136.

28. Stannard JP, Sheils TM, Lopez-Ben RR, McGwin G Jr., Robinson JT, Volgas DA (2004) Vascular injuries in knee dislocations: The role of physical examination in determining the need for arteriography. J Bone Joint Surg Am 86(5), 910-915.

29. Mills WJ, Barei DP, McNair P (2004) The value of the anklebrachial index for diagnosing arterial injury after knee dislocation: A prospective study. J Trauma 56(6), 1261-1265.

30. Stannard JP, Schreiner AJ (2020) Vascular injuries following knee dislocation. J Knee Surg 33(4), 351-356.

31. Peskun CJ, Whelan DB (2011) Outcomes of operative and nonoperative treatment of multiligament knee injuries: An evidence-based review. Sports Med Arthrosc Rev 19(2), 167-173.

32. Plancher KD, Siliski J. 2008. Long-term functional results and complications in patients with knee dislocations. J Knee Surg, 21, 261-268.

33. Moatshe G, Dornan GJ, Ludvigsen T, Løken S, LaPrade RF, Engebretsen L (2017) High prevalence of knee osteoarthritis at a minimum 10-year follow-up after knee dislocation surgery. Knee Surg Sports Traumatol Arthrosc 25(12), 3914-3922.

34. Richter M, Bosch U, Wippermann B, Hofmann A, Krettek C (2002) Comparison of surgical repair or reconstruction of the cruciate ligaments versus nonsurgical treatment in patients with traumatic knee dislocations. Am J Sports Med 30(5), 718-727.

35. Almekinders LC, Logan TC (1992) Results following treatment of traumatic dislocations of the knee joint. Clin Orthop Relat Res 284, 203-207.

36. Demirağ B, Oztürk C, Bilgen OF, Durak K (2004) Knee dislocations: an evaluation of surgical and conservative treatment. Ulus Travma Acil Cerrahi Derg 10(4), 239-244.

37. Ríos A, Villa A, Fahandezh H, de José C, Vaquero J (2003) Results after treatment of traumatic knee dislocations: a report of 26 cases. J Trauma 55(3), 489-494.

38. Wong CH, Tan JL, Chang HC, Khin LW, Low CO (2004) Knee dislocations-a retrospective study comparing operative versus closed immobilization treatment outcomes. Knee Surg Sports Traumatol Arthrosc 12(6), 540-544.

39. Giannotti BF (2004) Nonoperative treatment of the acutely dislocated knee, in The multiple ligament injured knee: A practical guide to management. Fanelli GC, Editor. New York, NY: Springer. p. 51-55.

40. Held M, North D, Bormann R, Wascher D, Richter D, Schenck $\mathrm{R}$ (2020) Advances and trends in multiligament injuries of the knee relevant to low-resource settings. J Arthrosc Surg Sports Med 1, 1-8.

41. Henrichs A (2004) A review of knee dislocations. J Athl Train, 39(4), 365-369.

42. Ng J, Myint Y, Ali F (2020) Management of multiligament knee injuries. EFORT Open Rev 5(3), 145-155.

43. Bin SI, Nam TS (2007) Surgical outcome of 2-stage management of multiple knee ligament injuries after knee dislocation. Arthroscopy 23(10), 1066-1072.

44. Ishibashi Y, Kimura Y, Sasaki E, Sasaki S, Yamamoto Y, Tsuda E (2020) Acute primary repair of extraarticular ligaments and staged surgery in multiple ligament knee injuries. J Orthop Traumatol 21(1), 18. 
45. Jiang W, Yao J, He Y, Sun W, Huang Y, Kong D (2015) The timing of surgical treatment of knee dislocations: a systematic review. Knee Surg Sports Traumatol Arthrosc, 23(10), 3108-3113.

46. Mook WR, Miller MD, Diduch DR, Hertel J, Boachie-Adjei Y, Hart JM (2009) Multiple-ligament knee injuries: A systematic review of the timing of operative intervention and postoperative rehabilitation. J Bone Joint Surg Am 91(12), 2946-2957.

47. Frosch K, Preiss A, Heider S, et al. (2013) Primary ligament sutures as a treatment option of knee dislocations: A metaanalysis. Knee Surg Sports Traumatol Arthrosc 21(7), 15021509.

48. Samuel L, Rabin J, Jinnah A, et al. (2019) Management of the multi-ligamentous injured knee: an evidence-based review. Ann Jt 4, 4-21.

49. Mariani P, Santoriello P, Iannone S, Condello V, Adriani E (1999) Comparison of surgical treatments for knee dislocation. Am J Knee Surg 12(4), 214-221.

50. Burrus MT, Werner BC, Griffin JW, Gwathmey FW, Miller MD (2016) Diagnostic and management strategies for multiligament knee injuries: a critical analysis review. JBJS Rev, 4, 2.

51. Stannard J, Brown S, Farris R, McGwin GJ, Volgas D (2005) The posterolateral corner of the knee: repair versus reconstruction. Am J Sports Med 33(6), 881-888.

52. Levy BA, Dajani KA, Morgan JA, Shah JP, Dahm DL, Stuart MJ (2010) Repair versus reconstruction of the fibular collateral ligament and posterolateral corner in the multiligament-injured knee. Am J Sports Med 38(4), 804-809.

53. Vermeijden HD, Jonkergouw A, van der List JP, DiFelice GS (2020) The multiple ligament-injured knee: When is primary repair an option? Knee, 27(1), 173-182.

54. Dabis J, Wilson A (2019) Repair and augmentation with internal brace in the multiligament injured knee. Clin Sports Med, 38(2), 275-283.

55. Ranger P, Renaud A, Phan P, Dahan P, De Oliveira E Jr., Delisle J (2011) Evaluation of reconstructive surgery using artificial ligaments in 71 acute knee dislocations. Int Orthop 35 (10), 1477-1482.

56. Heitmann M, Akoto R, Krause M, Hepp P, et al. (2019) Management of acute knee dislocations: Anatomic repair and ligament bracing as a new treatment option-results of a multicentre study. Knee Surg Sports Traumatol Arthrosc 27 (8), 2710-2718.

57. Venter S-M, Dey R, Khanduja V, von Bormann RP, Held M (2021) The management of acute knee dislocations: a global survey of orthopaedic surgeons' strategies. SICOT J 7, 21.

58. Mosquera M, Jaramillo A, Gil R, Gonzalez Y (2020) Controversies in acute multiligamentary knee injuries (MLKI). J Exp Orthop 7(1), 56.

59. Whelan D, Khan M, Rubacha M, Hoit G (2019) Early versus delayed surgery results in similar outcomes following multiligament knee injury; a prospective cohort. Orthop Sports Med 7 (7 supp15), 2325967119 S00299.

60. Vicenti G, Solarino G, Carrozzo M, et al. (2019) Major concern in the multiligament-injured knee treatment: a systematic review. Injury 50(Suppl 2), S89-S94.

61. Montgomery JB (1987) Dislocation of the knee. Orthop Clin North Am 18(1), 149-156.
62. Held M, Laubscher M, von Bormann R, Richter DL, Wascher DC, Schenck RC (2021) Open approaches for cruciate ligament reconstruction in knee dislocations: a technical note and case series. SICOT J 7, 17.

63. Lachman JR, Rehman S, Pipitone PS (2015) Traumatic knee dislocations: evaluation, management, and surgical treatment. Orthop Clin North Am 46(4), 479-493.

64. Ng JWG, Myint Y, Ali FM (2020) Management of multiligament knee injuries. EFORT Open Rev 5(3), 145-155.

65. Weiss NG, Kaplan LD, Graf BK (2003) Graft selection in surgical reconstruction of the multiple-ligament-injured knee. Oper Tech Sports Med 11(3), 218-225.

66. Lynch AD, Chmielewski T, Bailey L, et al. (2017) Current concepts and controversies in rehabilitation after surgery for multiple ligament knee injury. Curr Rev Musculoskelet Med 10 (3), 328-345.

67. Hantes M, Fyllos A, Papageorgiou F, Alexiou K, Antoniou I (2019) Long-term clinical and radiological outcomes after multiligament knee injury using a delayed ligament reconstruction approach: a single-center experience. Knee 26(6), 12711277.

68. Fanelli GC, Sousa PL, Edson CJ (2014) Long-term followup of surgically treated knee dislocations: stability restored, but arthritis is common. Clin Orthop Relat Res 472(9), 2712-2717.

69. Engebretsen L, Risberg MA, Robertson B, Ludvigsen TC, Johansen S (2009) Outcome after knee dislocations: a 2-9 years follow-up of 85 consecutive patients. Knee Surg Sports Traumatol Arthrosc 17(9), 1013-1026.

70. Woodmass JM, O’Malley MP, Krych AJ, et al. (2018) Revision multiligament knee reconstruction: clinical outcomes and proposed treatment algorithm. Arthroscopy 34(3), 736-744.e3.

71. Chahal J, Whelan DB, Jaglal SB, et al (2014) The multiligament quality of life questionnaire: development and evaluation of test-retest reliability and validity in patients with multiligament knee injuries. Am J Sports Med 42, 2906-2916.

72. Hatch GFR 3rd, Villacis D, Damodar D, Dacey M, Yi A (2018) Quality of life and functional outcomes after multiligament knee reconstruction. J Knee Surg 31(10), 970-978.

73. Poulsen E, Goncalves GH, Bricca A, Roos EM, Thorlund JB, Juhl CB (2019) Knee osteoarthritis risk is increased 4-6 fold after knee injury - a systematic review and meta-analysis. Br J Sports Med 53(23), 1454-1463.

74. Hirschmann MT, Zimmermann N, Rychen T, et al. (2010) Clinical and radiological outcomes after management of traumatic knee dislocation by open single stage complete reconstruction/repair. BMC Musculoskelet Disord 11, 102.

75. Everhart JS, Du A, Chalasani R, Kirven JC, Magnussen RA, Flanigan DC (2018) Return to work or sport after multiligament knee injury: a systematic review of 21 studies and 524 patients. Arthroscopy 34(5), 1708-1716.

76. Marom N, Ruzbarsky JJ, Roselaar N, Marx RG (2018) Knee MLI injuries: common problems and solutions. Clin Sports Med 37(2), 281-291.

77. Ekhtiari S, Horner N, de Sa D, et al. (2017) Arthrofibrosis after ACL reconstruction is best treated in a step-wise approach with early recognition and intervention: a systematic review. Knee Surg Sports Traumatol Arthrosc 25(12), 3929-3937. 